\title{
Estudo comparado da morfologia externa de Zaretis itys itylus (Westwood) e Agrias claudina annetta (Gray) (Lepidoptera, Nymphalidae, Charaxinae) l. Cabeça, apêndices e região cervical ${ }^{1}$
}

\author{
Carlos Guilherme C. Mielke ${ }^{2}$, Olaf H. H. Mielke ${ }^{3} \&$ Mirna M. Casagrande ${ }^{3}$ \\ ${ }^{1}$ Contribuição número 1291 do Departamento de Zoologia, Universidade Federal do Paraná. \\ ${ }^{2}$ Caixa postal 1206, 84145-000 Carambeí, Paraná, Brasil.E-mail: cmielke1@uol.com.br \\ ${ }^{3}$ Laboratório de Estudos de Lepidoptera Neotropical, Departamento de Zoologia, Universidade Federal do Paraná. \\ Caixa Postal 19020,81531-980 Curitiba, Paraná, Brasil. Pesquisador do CNPq. E-mail: omhesp@ufpr.br; mibras@ufpr.br
}

\begin{abstract}
Comparative study of the external morphology of Zaretis itys itylus (Westwood) and Agrias claudina annetta (Gray) (Lepidoptera, Nymphalidae, Charaxinae). I. Head, appendages and cervical region. Two species of Charaxinae, Zaretis itys itylus (Westwood, 1850) and Agrias claudina annetta (Gray, 1832) were subject of a detailed and comparative study of external morphology of the head, appendages and cervical region. The results obtained were compared with other studies published and related to the external morphology of other Nymphalidae subfamilies (Brassolinae, Morphinae, Danainae and Ithomiinae).

KEY WORDS. Butterflies, comparative study, morphology, Neotropical.
\end{abstract}

RESUMO. Realizou-se um estudo detalhado e comparado da morfologia externa da cabeça, apêndices e região cervical, de duas espécies de Charaxinae, Zaretis itys itylus (Westwood, 1850) e Agrias claudina annetta (Gray, 1832). Os resultados obtidos foram comparados com outros já publicados e relacionados com morfologia externa de outras subfamílias de Nymphalidae (Brassolinae, Morphinae, Danainae e Ithomiinae).

PALAVRAS CHAVE. Borboletas, estudo comparado, morfologia, Neotropical.

São conhecidas de 300 a 400 espécies de Charaxinae (ACKerY 1984), e entre estas pouco mais de uma centena são neotropicais. Juntamente com as espécies de Ornithoptera Boisduval, [1832] e Troides Hübner, [1819] (Lepidoptera, Papilionidae), algumas espécies de Charaxinae, representadas principalmente pelos gêneros Agrias Doubleday, 1844 e Prepona Boisduval, [1836], são consideradas as mais belas, raras, e conseqüentemente muito cobiçadas por colecionadores.

A ocorrência deste grupo no mundo está praticamente restrita à região entre os trópicos, sendo que o aparecimento em latitudes mais altas e climas temperados, é rara. A maior parte dos gêneros está na Região Neotropical com poucos de ocorrência nas Regiões Oriental, Oceania, Paleártica e Etiópica.

Com corpo robusto, tórax pronunciado e abdome relativamente pequeno, os Charaxinae mostram-se normalmente com vôo rápido, na maioria das vezes circulando pelo dossel superior das árvores, dificultando a visualização, entretanto, esta pode ser facilitada através de atração à iscas, como frutas e animais em decomposição, fezes, urina e suor. Costumam retornar ao mesmo local de alimentação, assim como ao seu território, muitas vezes, pontuais (Rydon 1971), seja em clareiras ou topos de morros. Tais comportamentos são verificados nas espécies brasileiras.

A subfamília Charaxinae foi elevada ao status de família por DoherTy (1886), baseando-se em cinco espécies de borboletas provenientes da Índia. Rydon (1971) trata da evolução do grupo e estabelece uma nova classificação com base em caracteres por ele levantados e por outros autores (ЕHRLich 1958a, Сомsтоск 1961) e considera Charaxinae no mesmo nível de Nymphalidae.

EhrLich (1958b) relata que Charaxinae é o único grupo dentro de Nymphalidae que possui parapatágios esclerotinizados, caracterizando desta forma uma apomorfia; menciona também que este grupo caracteriza-se por apresentar a célula discal posterior fechada por uma veia não tubular. RYDON (1971) diferencia Charaxinae dos demais Nymphalidae por apresentarem $\mathrm{R}_{4}$ e $\mathrm{R}_{5}$ muito maiores que o seu ramo comum, com $\mathrm{R}_{4}$ mostrando-se curvada para baixo na proximidade do seu término que pode ser na margem costal, no ápice ou na margem externa da asa. ACKery (1984), além da célula discal posterior fechada e dos parapatágios esclerotinizados, destaca a presença do anepisterno II como um esclerito distinto, o pré-episterno mesotorácico bem desenvolvido e a sutura pre-episternal variável.

Revista Brasileira de Zoologia 21 (2): 357-369, junho 2004 
No presente artigo adota-se a classificação de HARVEY (1991) que praticamente segue a mesma posição de Rydon (1971), considerando o grupo como uma subfamília de Nymphalidae e suas subfamílias com o status de tribo, com exceção de Zaretidinae e Anaeinae que passam a ser consideradas como subtribos de Anaeini, Zaretidina (como Zaretiditi) e Anaeina (como Anaeiti), respectivamente.

Os principais trabalhos sobre a morfologia de Nymphalidae, incluindo cabeça, tórax e abdome, tratam de quatro subfamílias: Danainae (Ehrlich 1958a), Brassolinae (CASAGRANDE 1979a, b, c), Morphinae (Bilotтa 1993, 1995a, b) e Ithomiinae (Bizarro et al. 2003a, b, c). Com intuito de uma melhor compreensão desta família apresenta-se, em três partes, um estudo pormenorizado da morfologia externa de duas espécies de Charaxinae: Zaretis itys itylus (Westwood, 1850) e Agrias claudina annetta (Gray, 1832). Essa primeira parte trata da cabeça e apêndices e, da região cervical.

\section{MATERIAL E MÉTODOS}

Os exemplares de Zaretis itys itylus e Agrias claudina annetta foram obtidos através de coletas com rede entomológica e de criações em cativeiro no município de Joinville, Santa Catarina. Em ambos os casos, os insetos foram mortos com auxílio de vidro letal. Tal procedimento fez-se necessário para que as estruturas se mantivessem intactas desde a coleta até o manuseio em laboratório, evitando assim qualquer pressão sobre o corpo do inseto. Quando os exemplares provieram de cativeiro, esperou-se de três a quatro dias para que as estruturas atingissem esclerotinização adequada. Foram dissecados dez machos e duas fêmeas de Zaretis itys itylus e cinco machos e uma fêmea de Agrias claudina annetta.

As asas foram removidas, o corpo e os apêndices fervidos em banho-maria em solução de hidróxido de potássio $(\mathrm{KOH})$ a $10 \%$ até o amolecimento dos tecidos e clarificação do exoesqueleto.

A descrição das duas espécies está baseada em exemplares machos e quando nas fêmeas foram identificadas diferenças, estas são mencionadas no texto. Detalhou-se a descrição de Zaretis itys itylus e para Agrias claudina annetta as diferenças com a anterior.

Os adultos estão figurados em tamanho natural e as escalas apresentadas nos desenhos representam um milímetro. Para as medidas do olho composto, considerou-se como altura a distância desde o vértice até a base, próximo ao palpo labial e, como largura desde a área páraocular até a margem externa, ambas em vista frontal.

\section{RESULTADOS}

\section{Considerações sobre a terminologia}

A terminologia empregada no presente estudo segue, principalmente, àquela adotada por EHrLIcH (1958a) no trabalho sobre a morfologia de Danaus plexippus (Linnaeus, 1758). Consi- derando-se as divergências na literatura quanto à nomenclatura de certas estruturas e novos conceitos apresentados em artigos mais recentes, comenta-se a seguir alguns destes aspectos.

Sorensen (1980) considera que o termo sutura tem sido empregado de forma errônea, que a origem da maioria das linhas é incerta, e adota o termo sulco. Para SNodgrass (1960) o termo sutura deve ser reservado para linhas que representam a fusão de dois escleritos, o que é confirmado por MATsuda (1973). SCOBLe (1992) usa o termo sulco para as estruturas presentes na cabeça e acredita que há uma concordância geral quanto à homologia dos termos dentro de Lepidoptera e de outras ordens, no entanto, utiliza o termo sutura quando trata do tórax. MAdDEn (1944) considera que a cabeça é estruturalmente simples e com poucos escleritos. MAtsuda (1973) divide a cabeça em áreas e SCOBLE (1992) complementa que estas não podem ser definidas precisamente em termos de desenvolvimento, sendo usadas apenas como referências pelos lepidopterólogos. As definições de sulco e sutura são distintas, portanto, as estruturas desta natureza devem estar enquadradas em um destes conceitos em função de sua origem. Como há distorções na literatura e falta de clareza quanto à formação destas, adota-se neste artigo a terminologia usada por EHRLIch (1958a).

MAdDen (1944), no estudo sobre Manduca sexta (Linnaeus, 1763), considera que a sutura frontal separa o frontoclípeo e o vértice. Michener (1952), Ehrlich (1958a), Sorensen (1980), Casagrande (1979a), Bilotta (1993), Duarte et al. (2001) e BizarRo et al. (2003a) mencionam tal sutura como sutura transfrontal.

SNOdgrass (1935) e MAdDEN (1944) consideram a presença do esclerito ocular, distinto do frontoclípeo pela sutura ocular. Tal terminologia é seguida por CaSAgRande ( 1979a), BiLotTa (1993) e Bizarro et al. (2003a) em estudos com espécies de Nymphalidae. Sorensen (1980), trabalhando com Glaucopsyche lygdamus (Doubleday, 1842) (Lycaenidae), discorda por haver dúvidas quanto a homologia destas estruturas em Papilionoidea e aquelas definidas por SNOdgrass (1935), seguindo EHrLich (1958a). Complementa especificando que há pelo menos três variações no conjunto área paraocular e sulco láterofacial; Zaretis e Agrias estariam enquadradas no tipo III, onde a sutura láterofacial encontra-se em duas porções: a primeira que corre paralela à margem interna do olho composto e a segunda presente entre a fóvea tentorial anterior e a sutura clipeolabral.

Madden (1944), Casagrande ( 1979a) e Bilotta (1993) descrevem que entre a fóvea tentorial anterior e a sutura clipeolabral situa-se a sutura subgenal, separando o frontoclípeo da área subgenal. Para ЕнRLICH (1958a) a sutura láterofacial estende-se desde a margem ventral do alvéolo antenal até a porção látero-dorsal do labro, contendo a fóvea tentorial anterior e indicando que a sutura clipeolabral estaria em continuação à sutura láterofacial. SORENSEN (1980) atribui à porção entre a fóvea tentorial anterior e a sutura clipeolabral o nome de seção clipeogenal da sutura láterofacial. Neste trabalho são usados os termos: área paraocular, sutura láterofacial e seção clipeogenal da sutura láterofacial. 
A definição do quetosema demanda maiores estudos, tanto EhrLich (1958a) quanto Sorensen (1980) referem-se às áreas sensoriais próximas ao vértice e sugerem que possa se tratar do órgão encontrado por JORDAN (1923). Utiliza-se aqui o termo quetosema, para esta estrutura.

O esclerito antenal é citado por MADDEN (1944), CASAGRANDE ( 1979a), BilotTa (1993), BizARro et al. (2003a). SoRENSEN (1980) cita a presença do sulco circunantenal ao redor da base das antenas e ainda cria o termo projeção antenal; a homologia das estruturas encontradas por este autor não fica evidente em Zaretis e Agrias, portanto, adota-se a terminologia de MADDEN (1944).

Ehrlich (1958a) considera que o vértice é delimitado anteriormente pela sutura transfrontal, lateralmente pelos alvéolos antenais e posteriormente pela sutura temporal. Menciona ainda, a presença de uma sutura chamada de paratemporal que corre paralela à sutura temporal, iniciando no soquete antenal e terminando junto à sutura pós-occipital. MADDEN (1944) chama a sutura paratemporal de sutura pós-genal. SoRENSEN (1980) refere-se à sutura paratemporal de EHRLICH (1958a) como sinônimo de sutura temporal. Segue-se a terminologia de SORENSEN (1980) para esta sutura.

Madden (1944), Lemaire (1971) e Sorensen (1980) consideram que a pós-gena ocupa o espaço entre o pós-occipício e os olhos compostos, estendendo-se ventralmente em continuação da área subgenal. Sorensen (1980) complementa que nos "Macrolepidoptera", onde a presença da sutura occipital é questionável, a pós-gena e o occipício são representados por apenas um esclerito chamado de área pós-genal-occipital, onde a sutura temporal apenas cruza esta porção, não delimitando área específica. A delimitação do occipício e do pós-occipício nas diferentes espécies é muito divergente. Michener (1952) e EHRLICH (1958a) consideram a pós-gena como área occipital e occipício, respectivamente; e pós-occipício como sendo um esclerito que posiciona-se dorso-lateralmente ao forame magno. Madden (1944), Casagrande ( 1979a), Bilotta (1993) e BizarRo et al. (2003a) referem-se ao occipício como uma área contígua ao vértice e ao esclerito pós-occipital ou pós-occipício como o que contorna o forame magno. Sorensen (1980) não separa em occipício, pós-occipício e pós-gena, cita-a apenas como área pós-genal-occipital, abrangendo estas porções. Pela própria definição dos termos, segue-se aqui a terminologia de MADDEN (1944), Casagrande ( 1979a) Bilotta (1993) e Bizarro et al. (2003a): pós-gena (contígua à sub-gena), occipício e pósoccipício.

O forame magno é dividido pela ponte tentorial (EHrLıcH 1958a, Michener 1952, Sorensen 1980, Duarte et al. 2001). Para Madden (1944), Casagrande ( 1979a), Bilotta (1993) e Bizarro et al. (2003a) esta estrutura recebe o nome de ponte pós-occipital. Pela posição que esta ocupa, segue-se MADDEN (1944).

Ventralmente, o forame magno é delimitado pelo esclerito labial (Ehrlich 1958a, Casagrande 1979a, Sorensen 1980, Bilotta 1993), que Madden (1944) chama de ponte hipostomal e Michener (1952) de ponte pós-occipital. Por haver concor- dância com a maioria dos autores mantém-se o termo empregado no texto base.

\section{Região cervical}

Para Madden (1944), Michener (1952), Ehrlich (1958a), CASAgrande (1979c), Bilotta (1995a), a região do cervical pertence ao tórax. MATSUDA (1973) menciona que em alguns Lepidoptera primitivos é fácil supor a origem pré-episternal do esclerito cervical. Scoble (1992) considera que esta região é derivada de elementos cefálicos e torácicos.

\section{Zaretis itys itylus (Westwood, 1850)} Figs 1-14

\section{Cabeça}

Hipognata, totalmente revestida de escamas, com as seguintes medidas: largura total 4,2 $\mathrm{mm}$; distância entre as bases dos olhos compostos na porção mediana do frontoclípeo 1,8 $\mathrm{mm}$; altura do olho medida na base $1,9 \mathrm{~mm}$; distância entre o dorso do frontoclípeo e a sutura clipeolabral 1,3 $\mathrm{mm}$; comprimento entre a margem anterior do frontoclípeo e o occipício $2 \mathrm{~mm}$; largura total em relação à altura do olho na razão 2,1 ; altura do olho 1,4 vezes maior que a mesma medida do frontoclípeo; distância interocular 1,5 vezes maior que a largura do olho, em vista frontal.

Em vista anterior destacam-se os olhos compostos glabros e globulares com a margem interna reta. Ocupando grande parte da cabeça, entre os olhos compostos e de aspecto quadrangular, o frontoclípeo; na sua metade superior, uma região central pouco mais esclerotinizada e com margem ventral arredondada; a margem dorsal encontra-se deprimida de tal forma que é possível a visualização da porção dorsal do vértice posteriormente; dorsalmente delimitado pela sutura transfrontal, localizada entre os alvéolos antenais, sem lamela interna; lateralmente demarcado pela sutura láterofacial com lamela interna pronunciada e separado da área paraocular, esta na base dos olhos compostos mais estreita medianamente; paralela e internamente à sutura láterofacial, uma carena pouco evidente frontalmente, a carena anterior; ventralmente duas áreas diferenciadas por linhas enrugadas, caracterizando vestígios do ante e pós-clípeo, nitidamente separados. O primeiro, retangular e com a margem dorsal deprimida medianamente, e o segundo, oval e afilado lateralmente, estão delimitados lateralmente pela sutura láterofacial, seção clipeogenal. Labro como um esclerito transverso separado do frontoclípeo pela sutura clipeolabral; com duas projeções laterais, uma de cada lado, os pilíferos, revestidos por inúmeras cerdas projetadas sobre a base das gáleas e na porção mediana, um pequeno lobo, a epifaringe. Separando látero-ventralmente o frontoclípeo da área subgenal, a sutura láterofacial, seção clipeogenal. A área subgenal estende-se ventralmente, circundando a fossa proboscidial, e termina na região posterior da cabeça látero-posteriormente à porção inferior do forame magno. A fóvea tentorial anterior, uma invaginação do tegumento, está contígua à sutura láterofacial, 

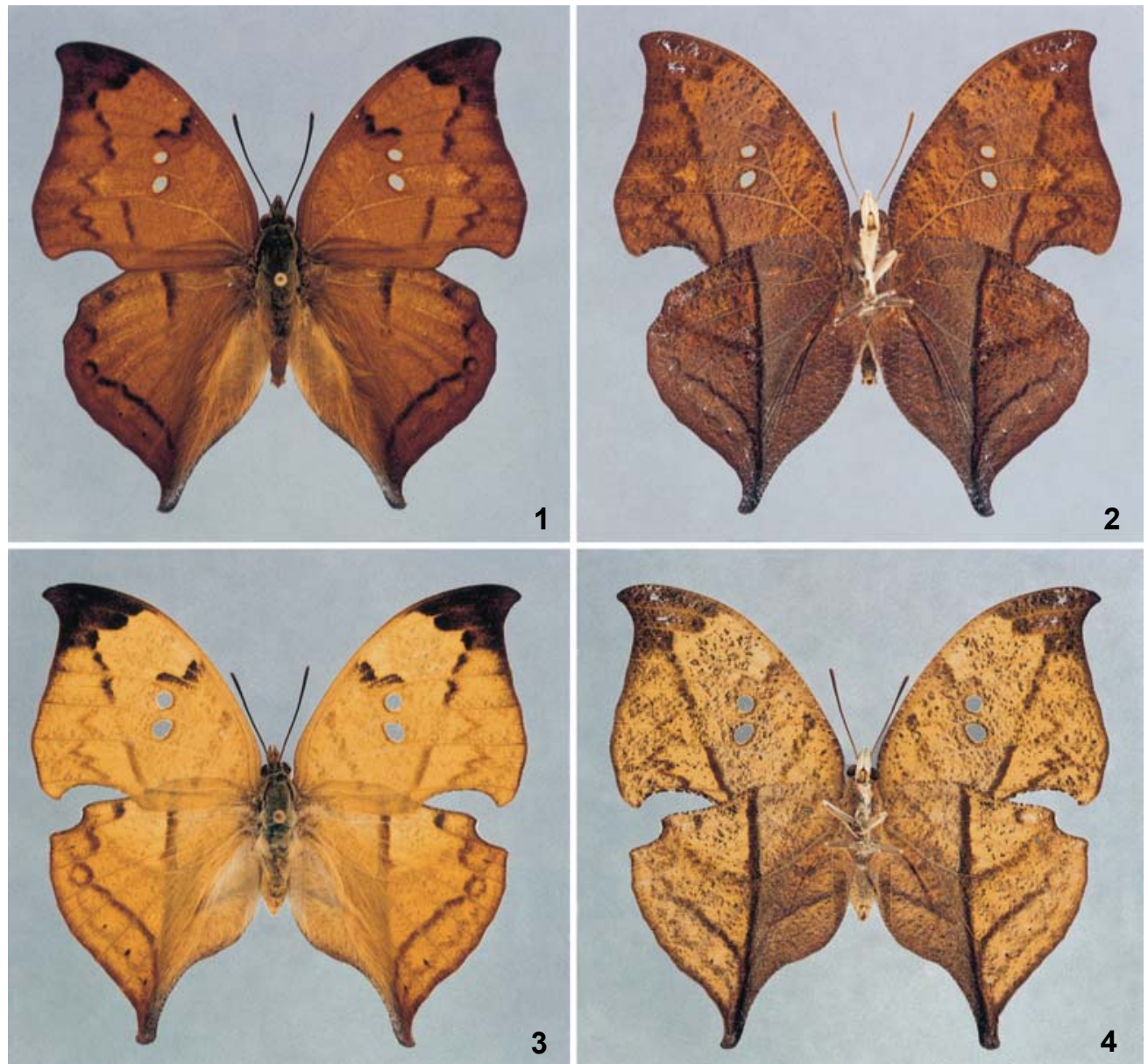

Figuras 1-4. Zaretis itys itylus: (1) macho, vista dorsal; (2) vista ventral; (3) fêmea, vista dorsal; (4) fêmea, vista ventral.

seção clipeogenal. Látero-dorsalmente à fóvea, vestígios da sutura láterofacial, fracamente delineada, estendida até às proximidades da área paraocular em sua porção mediana. $\mathrm{O}$ rudimento mandibular, localizado na parte interna da área subgenal e contíguo ao pilífero, apresenta-se com textura diferenciada e delimitado por uma dobra incompleta na base.

Em vista dorsal, a margem interna dos olhos compostos na altura dos alvéolos antenais mostra uma reentrância que promove um alargamento da pós-gena. Entre e posterior aos alvéolos antenais o vértice representado por uma porção anterior interantenal deprimida e outra posterior em forma de $\mathrm{W}$ elevado. A primeira, afasta os alvéolos na mesma proporção de seus diâmetros. A parte elevada, assim como a parte mediana dorsal do frontoclípeo, provida de pontuações mais claras e circundando-a, encontram-se algumas áreas sensitivas que caracterizam o quetosemata. Entre a margem posterior do alvéolo antenal e a anterior do W, uma faixa levemente curva e estreita, demarca a porção anterior do quetosema; está afilada lateralmente, estende-se póstero-ventralmente, curvando-se em direção à região mediana da cabeça e demarca a porção posterior que mostra sua margem externa inclinada próximo a $45^{\circ}$ em relação ao eixo mediano. Quetosematas quando observados em vista posterior, não estão unidos medianamente, e sim interrompidos por uma região deprimida de textura lisa. Em vista posterior, o vértice, retangular 2,3 vezes mais largo que alto. A lamela interna da sutura láterofacial, próximo das antenas, emite ramificações sob forma de sutura, formando lamelas secundárias. A primeira, ramo I, projeta-se lateralmente. Os ramos II e III delimitam a porção mediana do esclerito antenal, expandido látero-anteriormente. $\mathrm{O}$ esclerito antenal com uma projeção triangular em sua margem anterior para articulação com as antenas, o antenífero. A sutura temporal, um prolongamento da sutura láterofacial, acompanha o vértice lateralmente, terminando pouco marcada próximo ao forame magno.

Ventralmente, a margem interna dos olhos compostos apresenta um ângulo aberto na altura da convergência da carena posterior com a sutura láterofacial; já a margem externa em continuação à pós-gena, formando uma semicircunferência, 


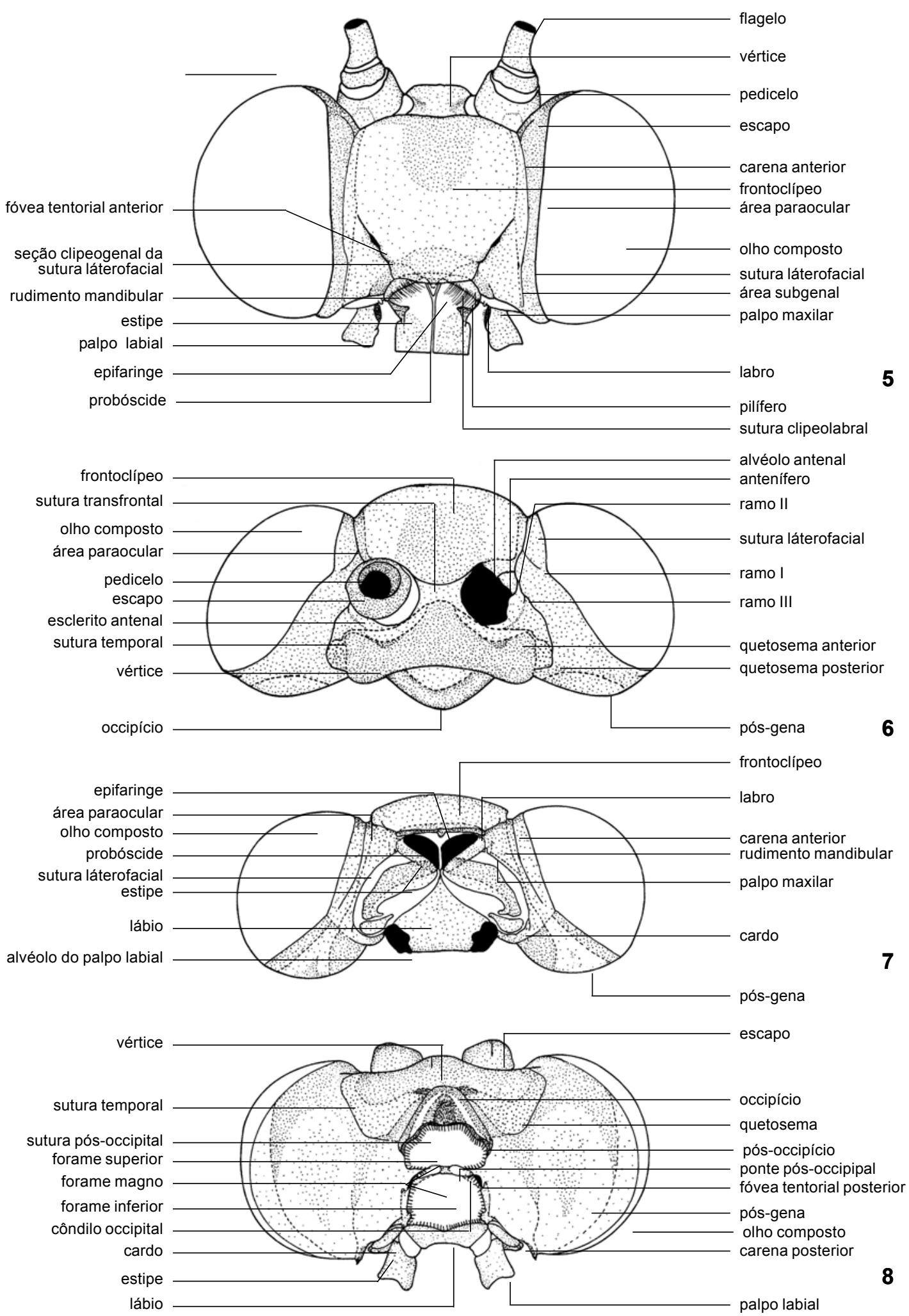

Figuras 5-8. Zaretis itys itylus, cabeça: (5) vista anterior; (6) vista dorsal; (7) vista ventral; (8) vista posterior. 


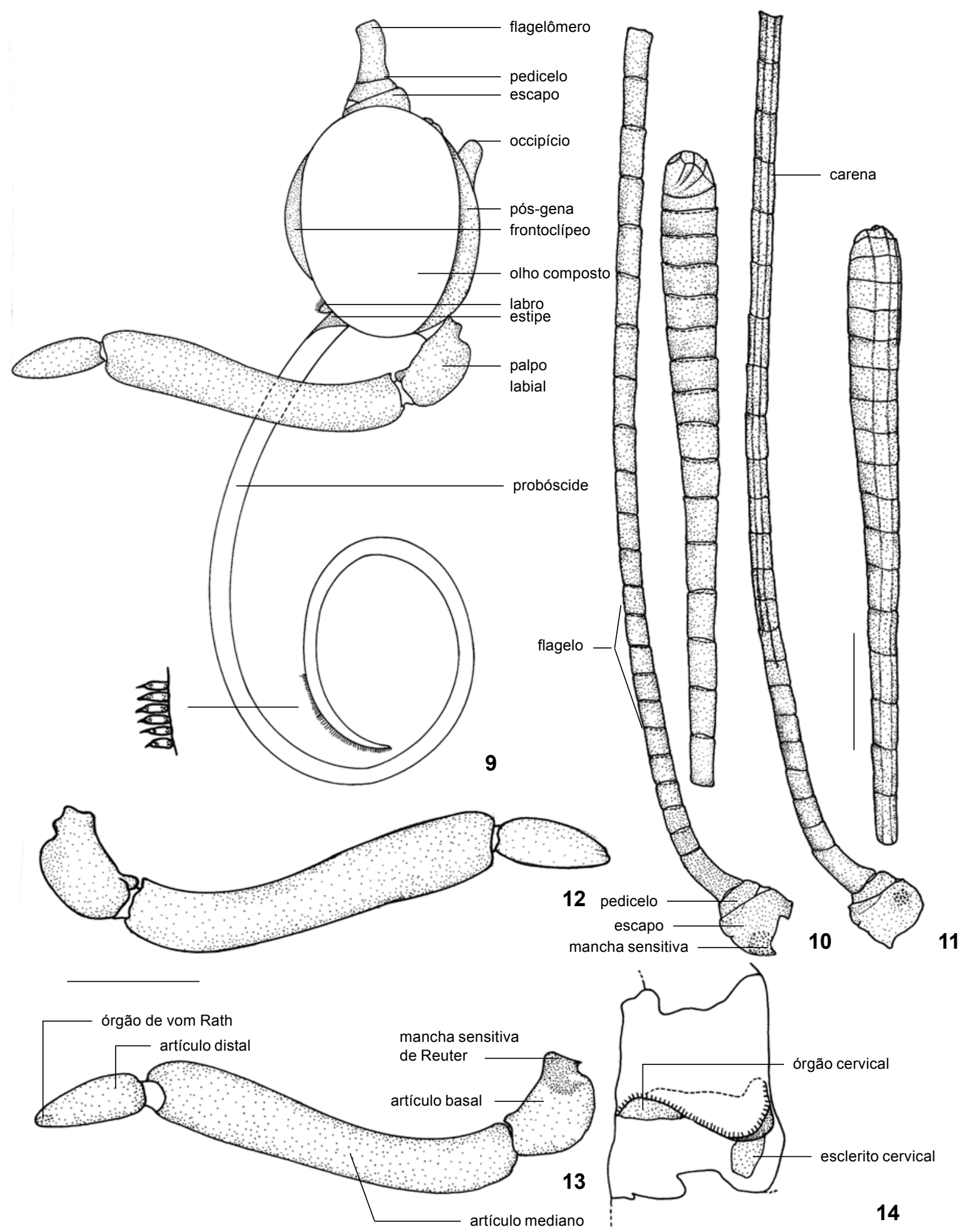

Figuras 9-14. Zaretis itys itylus: (9) cabeça vista lateral; (10-11) antena - (10) vista lateral externa, (11) vista lateral interna; (12-13) palpo labial - (12) vista lateral externa, (13) vista lateral interna; (14) região cervical.

Revista Brasileira de Zoologia 21 (2): 357-369, junho 2004 
destacando os olhos.

Em vista posterior, a pós-gena ocupa grande parte da região, com diferentes graus de esclerotinização, na parte central mais clara e provida de pontuações como aquelas do vértice, afastada da margem do olho por um terço da sua largura e do forame magno pelo terço proximal mais esclerotinizado. Este último separa-se ventralmente esta região clara pela carena posterior. A porção central é ocupada por uma grande abertura, o forame magno, dividida transversalmente pela ponte pósoccipital; logo forames superior e inferior. Ambos com a mesma largura, sendo o primeiro retangular, de ângulos láterodorsais côncavos e o segundo, quadrangular. Na ponte pósoccipital dois côndilos occipitais para a articulação da cabeça com os escleritos cervicais. Dorsalmente ao forame superior e póstero-ventral ao vértice encontra-se um esclerito triangular, projetado dorsalmente de altura e base proporcionais, o occipício. Este estende-se lateralmente até a região mediana do forame superior; apresenta na face posterior duas áreas sensitivas laterais com textura semelhante àquela do vértice e ao centro uma porção retangular de textura igual a da área entre as porções posteriores do quetosemata posterior. Ventralmente ao occipício e separado pela sutura pós-occipital, encontrase um esclerito estreito, o pós-occipício. Dorso-lateralmente ao forame inferior, encontram-se as fóveas tentoriais posteriores e ventralmente, a porção posterior do lábio. A pós-gena é delimitada ventralmente pela convergência da carena posterior e da margem posterior do olho composto que juntas com a carena anterior e a sutura láterofacial, direcionadas para o mesmo ponto, formam uma estrutura pontiaguda.

Em vista lateral, destaca-se o olho composto de forma oval. Frontoclípeo projetado anteriormente, mais largo medianamente. Pós-gena mais larga no terço ventral.

\section{Apêndices cefálicos}

Antenas com escamas, situam-se dorso-lateralmente ao frontoclípeo, com média de 46 artículos, tanto nos machos quanto nas fêmeas; unicolores e do tipo clavada, mostram um aumento progressivo dos artículos a partir do $28^{\circ}$. Escapo, robusto e achatado dorso-ventralmente, com pontuações mais claras, agrupadas em áreas distintas nas porções laterais interna e externa. Pedicelo anelar. Os primeiros flagelômeros são cônicos, com comprimento maior que a largura e nos últimos estas dimensões são opostas. As três carenas, na face interna, características de Nymphalidade desde o $8^{\circ}$ artículo até o último.

A porção central e ventral da cabeça é ocupada basicamente pela fossa proboscidial, onde o lábio, triangular e pouco esclerotinizado em relação pós-gena, ocupa a maior parte desta cavidade. Articula-se dorso-lateralmente com a pós-gena e com o cardo através da porção posterior; termina afilado entre a probóscide em forma de Y. Látero-posteriormente no lábio, o alvéolo do palpo labial. A maxila, formada pelo cardo, estipe, gálea e palpo maxilar, ocupa a parte restante da fossa proboscidial. O cardo, retangular e com a margem posterior arredondada, in- sere-se na parte basal externa do lábio posteriormente ao estipe. Este, articulado com o cardo e ladeado por membrana, apresenta-se em duas porções, uma basal que está em contato com o cardo e outra distal em ângulo quase reto com a parte basal da gálea; a primeira dividida longitudinalmente por uma carena, sendo a porção interna menos esclerotinizada; a segunda sustenta a gálea, envolvendo-a parcialmente. Aos lados, o rudimento mandibular e logo abaixo deste, o palpo maxilar.

A probóscide é cinco vezes maior que a altura da cabeça; enrolada e encaixada na fossa proboscidial quando em repouso; na base e abaixo do pilífero, um lóbulo membranoso e na face interna uma banda de fraca esclerotinização; distalmente, na margem lateral externa com papilas.

Palpo labial triarticulado, em forma de $\mathrm{S}$ e duas vezes mais largo que a probóscide em vista lateral, apresenta-se como um tubo espesso quando comparado à cabeça; artículo basal, de comprimento igual ao distal, possui na face interna a mancha sensitiva de Reuter; artículo mediano três vezes maior que o basal; distal, em forma de cone, possui no ápice uma estrutura quase imperceptível, o órgão de vom Rath.

\section{Região cervical}

Entre a cabeça e o tórax, uma área membranosa e pequena quando comparada com o restante do corpo é a região cervical. Lateralmente, os escleritos cervicais, um de cada lado, em forma de T, sendo que a base do T articula-se com a cabeça e a porção oposta ao protórax. O órgão cervical, uma área estreita, pequena e provida de cerdas, está presente na parte mediana ventral do esclerito, sendo visível apenas em vista ventro-lateral.

\section{Agrias claudina annetta (Gray, 1832) Figs 15-28}

\section{Cabeça}

Com as seguintes medidas: largura total 6,4 mm; distância entre as bases dos olhos compostos na porção mediana do frontoclípeo 2,4 mm; altura do olho medida na base $3,3 \mathrm{~mm}$; distância entre o dorso do frontoclípeo e a sutura clipeolabral 2,5 mm; comprimento entre a margem anterior do frontoclípeo e o occipício 3,0 mm; largura total em relação à altura do olho na razão 1,8 ; altura do olho 1,3 vezes maior que a mesma medida do frontoclípeo; distância interocular 1,4 vezes maior que a largura do olho, em vista frontal. Com aspecto mais alongado quando comparada com a espécie anterior.

Na porção inferior, abaixo do frontoclípeo, as duas regiões diferenciadas por linhas enrugadas, caracterizando vestígios do ante e pós-clípeo, parcialmente separados. O primeiro, quase inteiramente dividido pelo pós-clípeo e em forma de dois triângulos unidos pelos vértices, estende-se até a base da fóvea tentorial anterior por uma ponte e o segundo, losangular, afilado lateralmente. Ambos estão delimitados lateralmente pela sutura láterofacial, seção clipeogenal.

Em vistas frontal e dorsal a margem interna dos olhos compostos não apresenta reentância e portanto sem alarga-

Revista Brasileira de Zoologia 21 (2): 357-369, junho 2004 

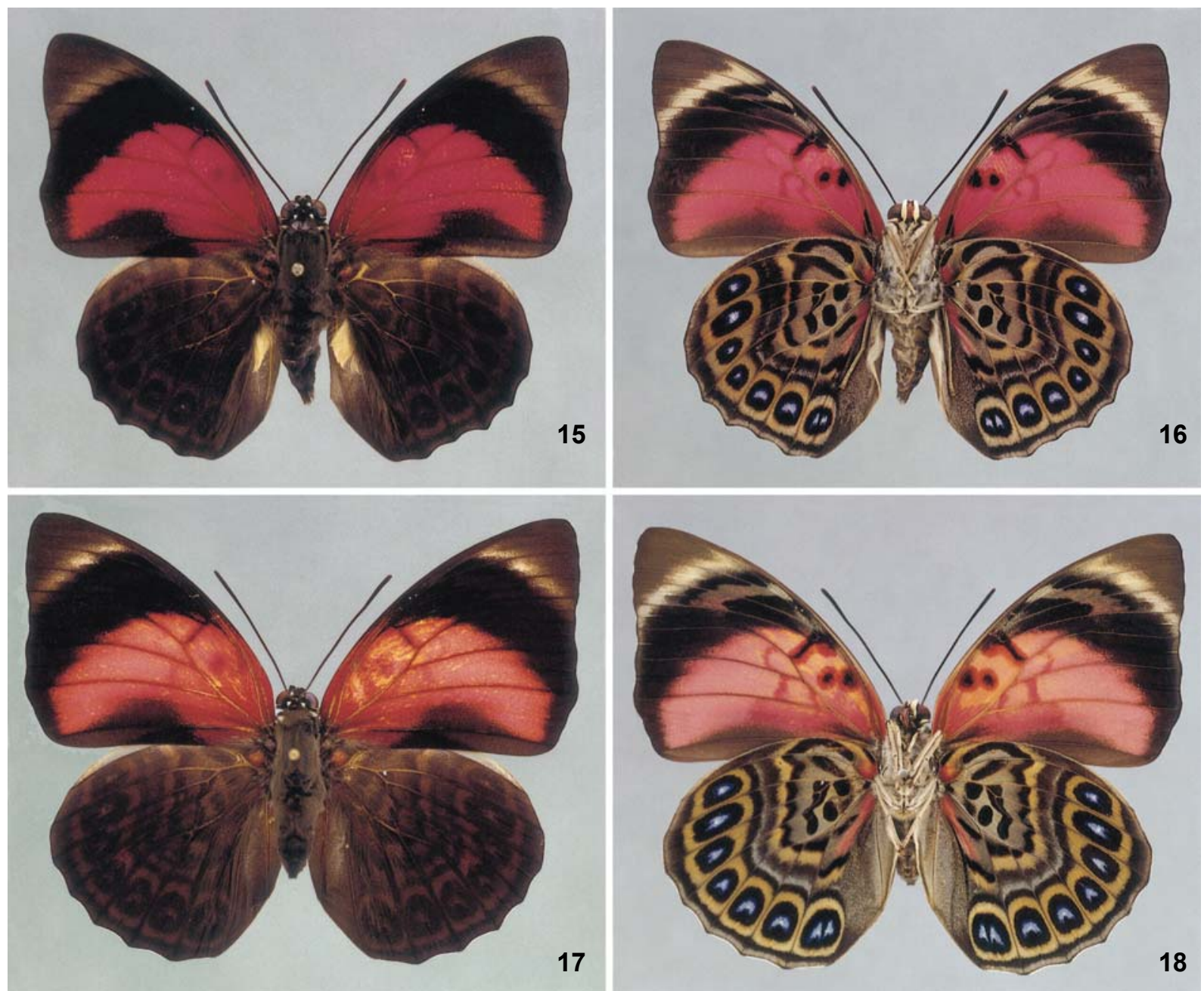

Figuras 15-18. Agrias claudina annetta: (15) macho, vista dorsal; (16) macho, vista ventral; (17) fêmea, vista dorsal; (18) fêmea, vista ventral.

mento da área pós-genal. Entre e posterior aos alvéolos antenais o vértice, representado por uma porção anterior interantenal deprimida e outra posterior em forma de W elevado. A primeira afasta os alvéolos a um terço de seus diâmetros. A parte elevada, assim como a parte mediana dorsal do frontoclípeo, provida com pontuações mais claras e circundando-a, encontramse algumas áreas sensitivas, caracterizando o quetosemata. Um de cada lado, o quetosema começa na porção dorsal da cabeça ao lado do $\mathrm{W}$ e estende-se póstero-ventralmente, curvando-se em direção a região mediana da cabeça que mostra sua margem externa inclinada próximo a $30^{\circ}$ em relação ao eixo mediano. Em vista posterior o vértice de aspecto retangular, mostra-se 1,92 vezes mais largo que alto.

Em vista ventral, a margem interna dos olhos compostos apresenta um ângulo próximo a $90^{\circ}$ na altura da convergência da carena posterior com a sutura láterofacial; já a mar- gem externa está em continuação à pós-gena, formando uma semicircunferência, destacando os olhos.

Em vista posterior, nota-se a pós-gena ocupando grande parte da região. Este esclerito apresenta-se com diferentes graus de esclerotinização, sendo caracterizados por uma parte central mais clara provida de pontuações como a da parte elevada do vértice, afastada da margem do olho por um nono da sua largura e do forame magno pelo terço proximal mais esclerotinizado, e separa-se ventralmente da região mais clara pela carena posterior. A porção central é ocupada por uma grande abertura, o forame magno, dividida transversalmente pela ponte pósoccipital; logo formam-se os forames superior e inferior. Ambos são retangulares, porém o primeiro mostra-se pouco mais largo que o segundo e apresenta as laterais arredondadas. Dorsalmente ao forame superior e póstero-ventral ao vértice encontra-se um esclerito triangular projetado dorsalmente e de 


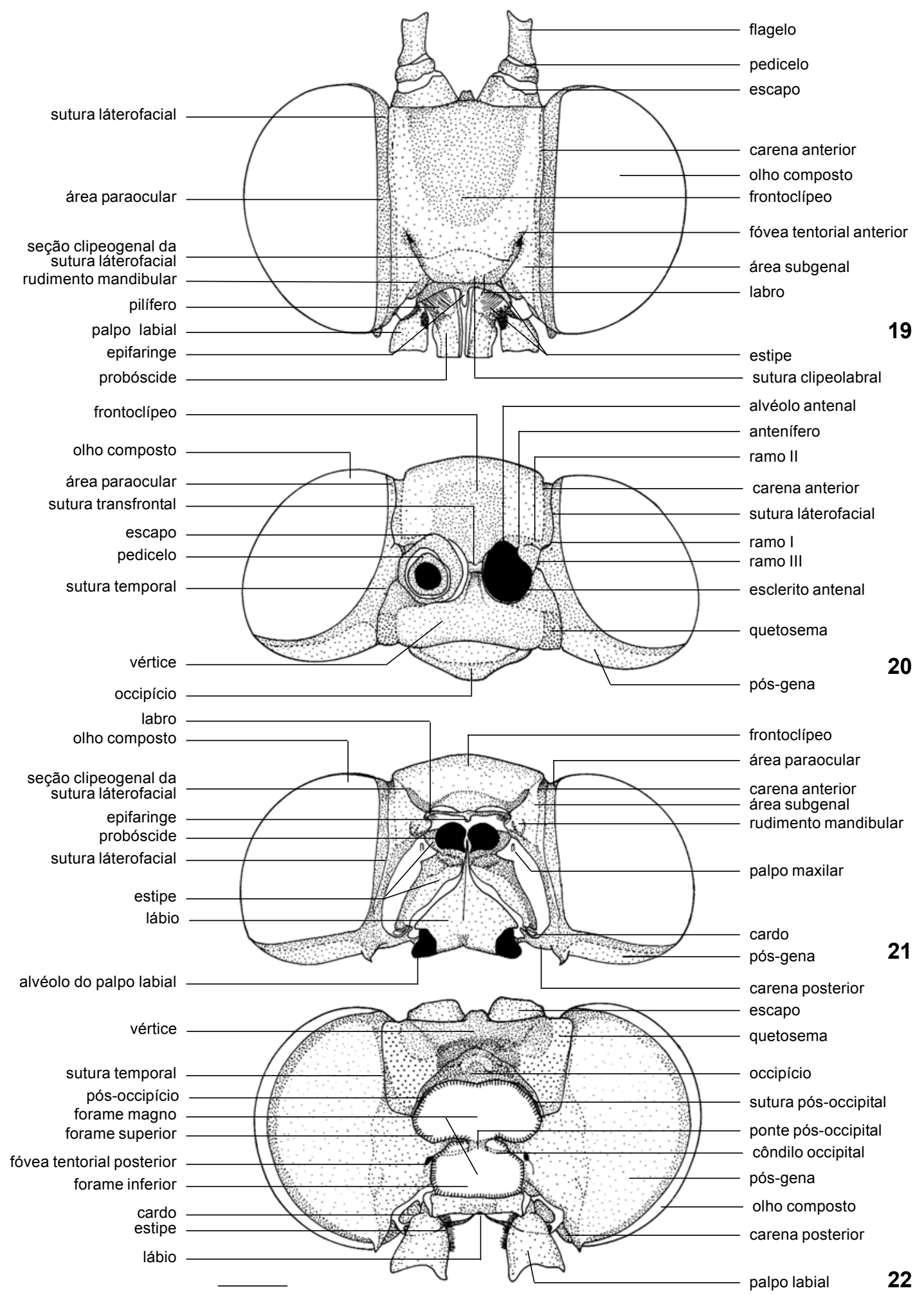

Figuras 19-22. Agrias claudina annetta, cabeça: (19) vista anterior; (20) vista dorsal; (21) vista ventral; (22) vista posterior. 

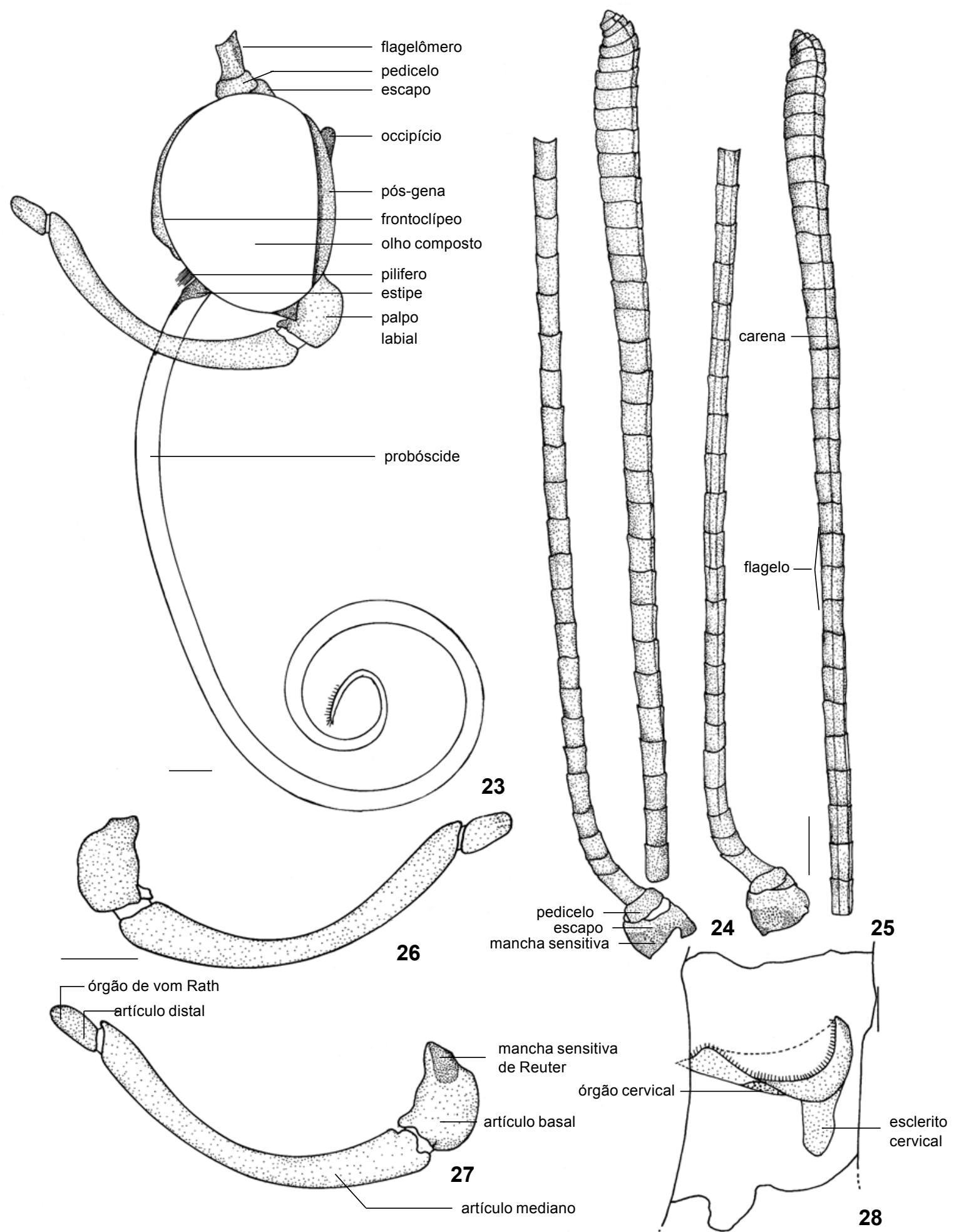

Figuras 24-28. Agrias claudina annetta: (23) cabeça vista lateral; (24-25) antena - (24) vista lateral externa, (25) vista lateral interna; (26-28) palpo labial - (26) vista lateral externa, (27) vista lateral interna; (28) região cervical.

Revista Brasileira de Zoologia 21 (2): 357-369, junho 2004 
Tabela I. Comparação resumida das diferenças encontradas entre as espécies em analisadas.

\begin{tabular}{|c|c|c|}
\hline Caracteres & Zaretis itys itylus & Agrias claudina annetta \\
\hline Razão entre a largura total e altura do olho & 2,1 & 1,8 \\
\hline $\begin{array}{l}\text { Razão entre a altura dos olhos compostos e a mesma } \\
\text { medida do frontoclípeo }\end{array}$ & 1,4 & 1,3 \\
\hline $\begin{array}{l}\text { Razão entre a distância interocular e a largura do olho } \\
\text { composto }\end{array}$ & 1,5 & 1,4 \\
\hline Ante e pós-clípeo & nitidamente separados & parcialmente separados \\
\hline Formato do ante-clípeo & retangular & dois triângulos unidos pelo vértice \\
\hline Formato do pós-clípeo & oval & losangular \\
\hline Sutura laterofacial, após a fóvea tentorial anterior & $\begin{array}{l}\text { fracamente delineada e estendida até as } \\
\text { proximidades da área paraocular }\end{array}$ & $\begin{array}{l}\text { quase imperceptível e pouco } \\
\text { estendida }\end{array}$ \\
\hline $\begin{array}{l}\text { Razão entre as larguras do alvéolo antenal e a da } \\
\text { porção anterior do vértice }\end{array}$ & 1 & 3 \\
\hline Quetosema anterior & presente & ausente \\
\hline $\begin{array}{l}\text { Ângulo formado pela margem interna da porção } \\
\text { posterior do quetosema em relação ao eixo mediano }\end{array}$ & próximo a $45^{\circ}$ & próximo a $30^{\circ}$ \\
\hline $\begin{array}{l}\text { Razão entre a largura e altura do vértice em vista } \\
\text { posterior }\end{array}$ & 2,3 & 1,92 \\
\hline $\begin{array}{l}\text { Razão entre as larguras da porção mais clara (central) } \\
\text { e a da porção mais escura (externa) da pós-gena }\end{array}$ & 3 & 9 \\
\hline Razão entre as larguras do forame superior e inferior & 1 & 1,4 \\
\hline Forame magno superior & apresenta ângulos látero-dorsais côncavos & apresenta laterais arredondadas \\
\hline Forame magno inferior & quadrangular & retangular \\
\hline Razão entre a base e a altura do occipício & 1 & 3 \\
\hline $\begin{array}{l}\text { Formato de uma área distinta presente na face } \\
\text { posterior do occipício }\end{array}$ & retangular & $U$ invertido \\
\hline $\begin{array}{l}\text { Ângulo presente na margem interna dos olhos } \\
\text { compostos, em vista ventral }\end{array}$ & aberto & fechado, próximo a $90^{\circ}$ \\
\hline Porção posterior mais esclerotinizada no lábio & ausente & presente \\
\hline Formato do olho composto em vista lateral & oval & oval, com base achatada \\
\hline $\begin{array}{l}\text { Porção do frontoclípeo projetada anteriormente em } \\
\text { vista lateral }\end{array}$ & mediana & ventral \\
\hline $\begin{array}{l}\text { Porção da pós-gena projetada posteriormente, em } \\
\text { vista lateral }\end{array}$ & terço ventral & mediana \\
\hline $\begin{array}{l}\text { Razão entre o comprimento da probóscide e a altura } \\
\text { da cabeça }\end{array}$ & 5 & 6 \\
\hline Número médio de artículos na antena & 46 & 60 \\
\hline Padrão de coloração da antena & unicolor & $\begin{array}{l}\text { últimos cinco artículos } \\
\text { diferenciados }\end{array}$ \\
\hline Artículo onde iniciam-se as carenas na antena & oitavo & sexto \\
\hline Formato do palpo labial & $S$ & curvado para cima \\
\hline Razão entre as largura do palpo labial e da probóscide & 2 & 1 \\
\hline $\begin{array}{l}\text { Razão entre o comprimento dos artículos mediano e } \\
\text { basal do palpo labial }\end{array}$ & 3 & 4,5 \\
\hline
\end{tabular}


altura menor em três vezes a sua base, o occipício. Este estende-se lateralmente até a região mediana do forame superior; apresenta na face posterior duas áreas sensitivas laterais com textura semelhante àquela do vértice e ao centro uma textura igual à da área entre a porções posteriores do quetosemata em forma de U invertido.

Em vista lateral destaca-se o olho composto de base chata. Frontoclípeo projetado anteriormente, mais largo ventralmente. Pós-gena mais larga medianamente.

\section{Apêndices cefálicos}

Antenas com escamas, situam-se dorso-lateralmente ao frontoclípeo, possuindo em média 60 artículos, tanto nos machos quanto nas fêmeas; últimos cinco artículos amarelados e do tipo clavada, mostra um aumento progressivo dos artículos a partir da região do $35^{\circ}$ e redução a partir dos últimos cinco. As carenas, na face interna, iniciadas a partir do sexto artículo e estendidas até o último.

A probóscide é seis vezes maior que a altura da cabeça; enrolada e encaixada na fossa proboscidial quando em repouso; na base, um lóbulo membranoso dorsalmente, e na face interna uma banda de fraca esclerotinização por toda sua extensão; distalmente, na margem lateral externa com papilas.

Palpo labial triarticulado e de largura semelhante à probóscide em vista lateral, apresenta-se como um tubo curvado para cima. O artículo basal, de comprimento igual ao distal, possui na face interna a mancha sensitiva de Reuter. O mediano, 4,5 vezes maior que o basal, é o maior.

\section{REFERÊNCIAS BIBLIOGRÁFICAS}

ACKERY, P.R. 1984. Systematic and faunistic studies on butterflies, p. 9-21. In: R.I. VAne-Wright \& P.R. Ackery (Eds). The Biology of Butterflies. London, Academic Press, 429p.

BıLotTA, I.G. 1993. Morfologia comparada da cabeça das espécies sulbrasileiras de Morphinae (Lepidoptera, Nymphalidae). Revista Brasileira de Zoologia, Curitiba, 9 (3/4): 261-271. . 1995. Morfologia comparada do tórax das espécies sulbrasileiras de Morphinae (Lepidoptera, Nymphalidae). Revista Brasileira de Zoologia, Curitiba, 11 (4): 691-713.

- 1993. Morfologia comparada do abdome das espécies sulbrasileiras de Morphinae (Lepidoptera, Nymphalidae). Revista Brasileira de Zoologia, Curitiba, 11 (4): 737 748.

Bizarro, J.M..; M.M. Casagrande \& O.H.H. Mielke. 2003 a. Morfologia externa de Thyridia psidii cetoides (Rosemberg \& Talbot). I. Cabeça e apêndices (Lepidoptera, Nymphalidae, Ithomiinae). Revista Brasileira de Zoologia, Curitiba, 20 (2): $279-284$.

- 2003b. Morfologia externa de Thyridia psidii cetoides (Rosemberg \& Talbot). II. Tórax e apêndices (Lepidoptera, Nymphalidae, Ithomiinae). Revista Brasileira de Zoologia, Curitiba, 20 (3): 419-425.

. 2003c. Morfologia externa de Thyridia psidii cetoides
(Rosemberg \& Talbot). IV. Abdome e apêndices (Lepidoptera, Nymphalidae, Ithomiinae). Revista Brasileira de Zoologia, Curitiba, 20 (4): 681-684.

Casagrande, M.M. 1979a. Sobre Caligo beltrao (Illiger). II: Morfologia externa da cabeça do adulto (Lepidoptera, Satyridae, Brassolinae). Revista Brasileira de Biologia, Rio de Janeiro, 39 (1): 223-227.

. 1979b. Sobre Caligo beltrao (Illiger). III: Morfologia externa do adulto - tórax (Lepidoptera, Satyridae, Brassolinae). Revista Brasileira de Biologia, Rio de Janeiro, 39 (2): 347-355.

. 1979c. Sobre Caligo beltrao (Illiger). IV: Morfologia externa do adulto - abdome (Lepidoptera, Satyridae, Brassolinae). Revista Brasileira de Biologia, Rio de Janeiro, 39 (3): 711-716.

Сомsтоск, W.P. 1961. Butterflies of the American Tropics. The genus Anaea Lepidoptera Nymphalidae. A study of the species heretofore included in the genera Anaea, Coenophlebia, Hypna, Polygrapha, Protogonius, Siderone and Zaretis. New York, American Museum of Natural History, XIII+214p.

DoherTy, W. 1886. A list of Butterflies taken in Kumaon. Journal Asiatic Society of Bengal 55 (2): 103-140.

Duarte, M.; M.M. Casagrande \& O.H.H. Mielke. 2001. Morfologia externa do adulto de Hemiargus hanno (Stoll) (Lepidoptera, Lycaenidae, Polyommatinae, Polyommatini). I Cabeça. Revista Brasileira de Zoologia, Curitiba, 18 (1): 225-238.

EHrLICH, P.R. 1958a. The integumental anatomy of the monarch butterfly Danaus plexippus L. (Lepidoptera: Danaidae). University of Kansas Science Bulletin, Lawrence, 38 (18): 1315-1349.

. 1958b. The comparative morphology, phylogeny and classification of the butterflies (Lepidoptera: Papilionoidea). University of Kansas Science Bulletin, Lawrence, 39 (8): 305-370.

Harvey, D.J. 1991. Appendix B. Higher Classification of the Nymphalidae, p. 225-273. In: H.F. NiJHOut (Ed.). The development and evolution of butterfly wing patterns. Washington, D.C., Smithsonian Institution Press, XIII+297p.

JORDAN, K. 1923. On a sensory organ found on the head of many Lepidoptera. Novitates Zoologicae, Tring, 30: 155-158.

Lemaire, C. 1971. Révision du genre Automeris Hübner et des genres voisins biogéographie, éthologie, morphologie, taxonomie (Lep. Attacidae). Mém. Mus. Nat. d'Hist. Nat. Paris, (A) 68: 1-232; 79: 233-422; 92: 424-576.

MADDEN, A.H. 1944. The external morphology of the adult tobacco hornworm (Lepidoptera, Sphingidae). Annals of the Entomological Society of America, New York, 27 (2): 145160.

MatsudA, R. 1973. Morphology and evolution of the insect head. Memoirs of the American Entomological Institute, Ann Arbor, 4: 1-334.

Michener, C.D. 1952. The Saturniidae (Lepidoptera) of the 
western hemisphere. Bulletin of the American Museum of Natural History, New York, 98 (5): 337-501.

Rydon, A.H.B. 1971. The systematics of the Charaxidae (Lepidoptera: Nymphaloidea). Entomologist's Record and Journal of Variation, London, 83 (8): 219-233; (9): 283-287; (10): 310-316; (11): 336-341; (12): 384-388.

Scoble, M. 1992. The Lepidoptera, form, function and diversity. Natural History Museum Publications-Oxford University Press, 404p.
SNODGRASS, R.E. 1935. Principles of insect morphology. New York, McGrow-Hill Book Company, 667p.

- 1960. Facts and theories concerning the insect head. Smithsonian Miscellaneous Collections, Washington, D.C., 142: 1-61.

SORENSEN, J.T. 1980. An integumental anatomy for the butterfly Glaucopsyche lygdamus (Lepidoptera: Lycaenidae): a morphological terminology and homology. Zoological Journal of the Linnean Society, London, 70: 55-101.

Recebido em 06.VI.2003; aceito em 05.VI.2004. 